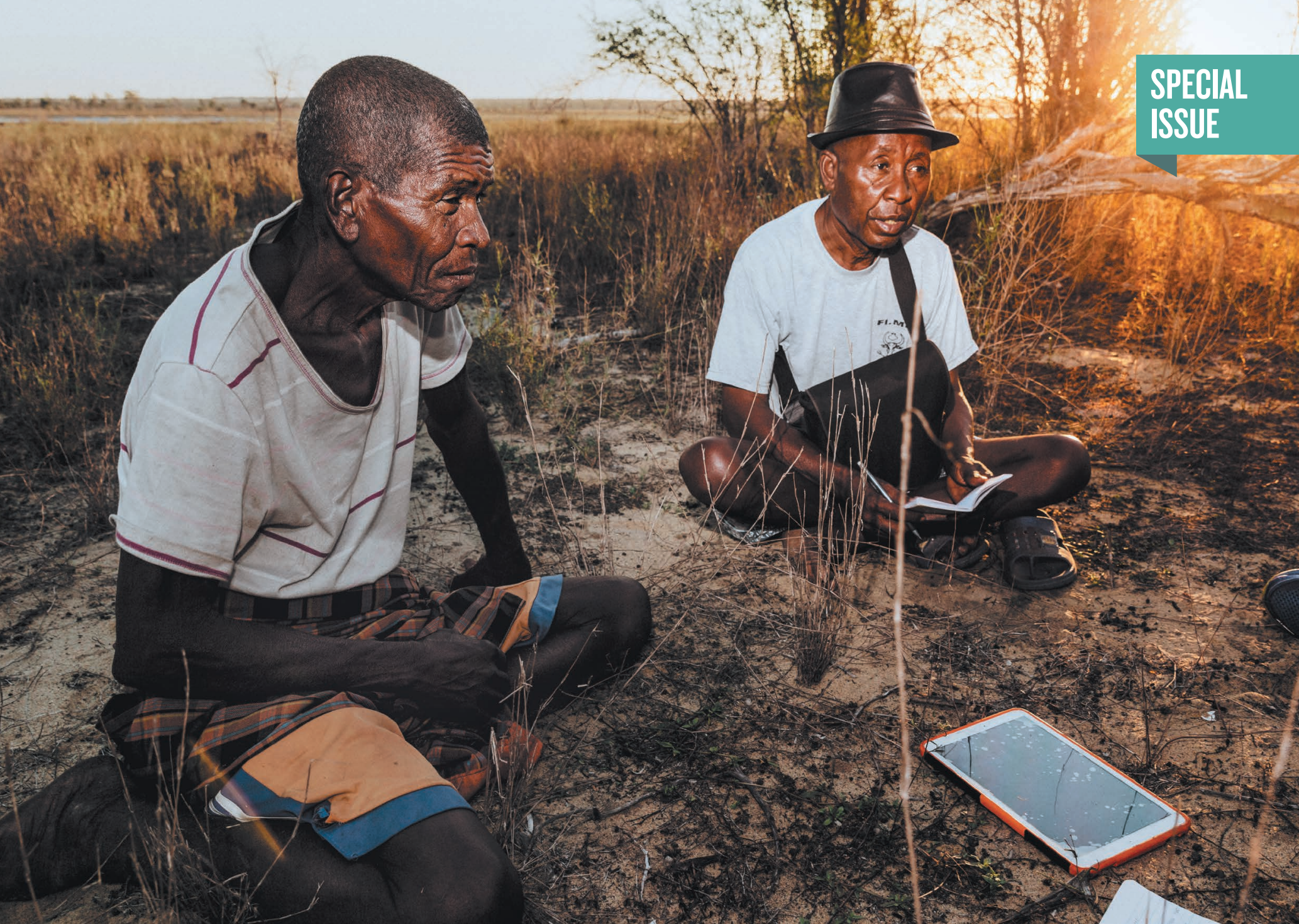

\title{
Science shared
}

\section{Those who were once the subjects of scientific enquiry are increasingly in the driver's seat. A special issue explores the co-production of research.}

$\mathrm{F}$

Trom people with HIV selecting which trials of antiviral therapies get funded, to farmers of smallholdings guiding weather monitoring, the people affected by research are increasingly getting involved in it. They are shaping how projects are conceived, supported, done, assessed, disseminated and rated. They are partners in research production.

This special issue looks at the promise and the pitfalls of co-production for the stakeholders, scientists and societies now working shoulder to shoulder. As one advocate describes it: "It's about getting everybody round the table so you're valuing the knowledge everybody has."

A series of case studies on page 24 illustrates the many forms such research can take. They include a public-health researcher who has been working to curb childhood obesity with members of the Osage Nation, a Native American community in Oklahoma; and climate modellers embedded with city planners in nine southern African cities to help determine the research and infrastructure needed to adapt to climate change. The stories highlight common themes: co-production takes people out of their comfort zones, but the pay-off comes in the form of enhanced trust and communication. Importantly, the research has a much better chance of making a difference to the people involved.

Those who were previously outside the academic system are also becoming gatekeepers for research: helping to decide what gets funded, published and evaluated. A collection of Comment articles describes how patients and carers are invited to review manuscripts at The BMJ (see page 30) and grant applications at the California Institute for Regenerative Medicine (see page 31). In some cases, they encourage risk-taking, in others, they rein in false hope. Another article calls for the wider use of co-created evaluation tools to improve and incentivize research co-production (see page 32).

So how do you join the revolution? Public-involvement manager Gary Hickey offers five principles for co-producing research on page 29. Chief among these is to share power. But, as he writes,

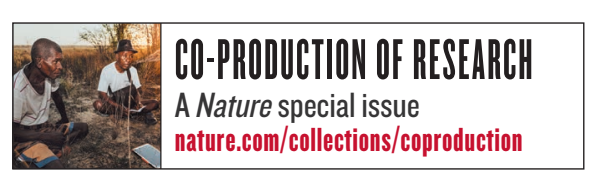
co-production won't happen just because it is a good thing: research partners need to change their practices and cultures. Getting everybody around the table is worthwhile, but it takes work. 